\title{
Growth factor purification and delivery systems (PADS) for therapeutic angiogenesis
}

\author{
Vascular Cell 7:3 I DOI: 10.1186/s13221-014-0026-3 I C Li et al.; licensee Publiverse Online S.R.L. 2015 \\ Received: 25 Aug 2014 I Accepted: 16 Aug 2014 I Published: 24 Aug 2015 \\ George Eric M, Liu Huiling, Robinson Grant G, Mahdi Fakhri, Perkins Eddie, Bidwell Gene L ${ }^{@}$ \\ ${ }^{+}$Contributed equally ${ }^{\circledR}$ Corresponding author
}

\section{Abstract}

\section{Background}

Therapeutic angiogenesis with vascular endothelial growth factor (VEGF), delivered either via recombinant protein infusion or via gene therapy, has shown promise in preclinical models of various diseases including myocardial infarction, renovascular disease, preeclampsia, and neurodegenerative disorders. However, dosing, duration of expression, and tissue specificity are challenges to VEGF gene therapy, and recombinant VEGF delivery suffers from extremely rapid plasma clearance, necessitating continuous infusion and/or direct injection at the site of interest.

\section{Methods}

Here we describe a novel growth factor purification and delivery system (PADS) generated by fusion of VEGF 121 to a protein polymer based on Elastin-like Polypeptide (ELP). ELP is a thermally responsive biopolymer derived from a five amino acid repeat sequence found in human tropoelastin. VEGFPADS were constructed by fusion of the ELP coding sequence in-frame with the VEGF ${ }_{121}$ coding sequence connected by a flexible di-glycine linker. In vitro

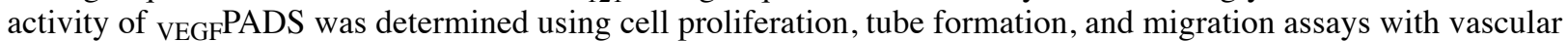
endothelial cells. Pharmacokinetics and biodistribution of VEGFPADS in vivo were compared to free VEGF in mice using quantitative fluorescence techniques.

\section{Results}

ELP fusion allowed for recombinant expression and simple, non-chromatographic purification of the ELP-VEGF ${ }_{121}$ chimera in yields as high as $90 \mathrm{mg} / \mathrm{L}$ of culture and at very high purity. ELP fusion had no effect on the VEGF

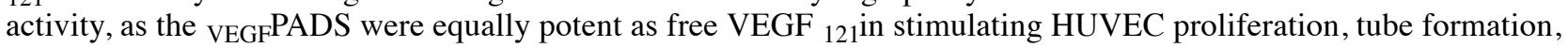
and migration. Additionally, the $\mathrm{VEGF}_{\mathrm{PADS}}$ had a molecular weight five-fold larger than free VEGF 121 , which lead to slower plasma clearance and an altered biodistribution after systemic delivery in vivo .

\section{Conclusion}

PADS represent a new method of both purification and in vivo stabilization of recombinant growth factors. The use of this system could permit recombinant growth factors to become viable options for therapeutic angiogenesis in a number of disease models.

\section{Keywords}

Vascular endothelial growth factor - Elastin-like polypeptide - Drug delivery - Therapeutic angiogenesis Purification and delivery system

\section{Background}

Loss of VEGF signaling or increase in anti-angiogenic factors have been implicated in many diseases including preeclampsia [ 1], renovascular disease [2], and neurodegenerative diseases [ 3,4]. Therapeutic angiogenesis with 
supplemental VEGF administration has shown preclinical efficacy in multiple animal models [ 4- 10]. However, due to its short plasma half-life and susceptibility to degradation, exogenous VEGF must be continuously administered, often directly at the desired site of action, to achieve therapeutic benefit. The goal of this study is to characterize a biopolymer fusion with human VEGF. Fusion with this biopolymer, a synthetic protein based on human elastin, allows for recombinant production of large amounts of the chimeric protein, very simple nonchromatographic purification, and reduced plasma clearance relative to free VEGF.

Supplemental VEGF has been supplied in several preclinical disease models by either direct administration of the recombinant protein or by gene therapy techniques. In a dog model of myocardial infarction, direct infusion of VEGF at the infarcted site improved blood flow and increased neovasc ular development [ 10]. However, daily infusion for 28 days directly at the site of the infarcted tissue was required. Similarly, continuous VEGF infusion into the myocardium for six weeks decreased the size of the ischemic zone and improved cardiac function in a swine model of myocardial infarction [ 8]. In renovascular disease, microvascular rarefaction associated with renal artery stenosis was associated with a marked reduction in bioavailable VEGF in the kidney [2], and intrarenal administration of VEGF improved renal function, increased microvessel density, and improved renal scarring in a swine model of renal artery stenosis [ 6]. In preeclampsia, increased production of the VEGF antagonist sFlt-1 has been shown to be a major driver of the maternal syndrome [ 11- 14]. Direct administration of recombinant VEGF via continuous intraperitoneal infusion sequestered the increased circulating sFlt-1 and reduced the hypertension [ 5]. VEGF supplementation has also shown efficacy in preclinical models of neurodegenerative diseases. In spinocerebellar ataxia type I (SCA1), VEGF mRNA and protein levels were decreased in the Purkinje layer of SCA1 transgenic mice, and VEGF administration improved the cerebellar pathology and the motor function in these mice [ 4]. However, direct intracerebroventricular administration was required. Similarly, loss of hypoxia inducible VEGF in neural tissue in transgenic mice lead to degeneration of lower motor neurons, causing a syndrome similar to amyotrophic lateral sclerosis [ 3]. In vitro, VEGF protected motor neurons from apoptosis induced by several stressors, and in vivo, VEGF protected dorsal root ganglion neurons against paclitaxel or hyperglycemia-induced neurotoxicity [7].

These results suggest value for supplemental VEGF therapy in a myriad of disease models. However, they also highlight several drawbacks to recombinant VEGF therapy. VEGF has a very short plasma half-life. In humans, a terminal half-life of 33.7 minutes was measured after a 20 minute infusion [ 15]. For this reason, continuous administration, often directly at the target site, is required for efficacy. To overcome this limitation, sustained release methods have been developed. VEGF-loaded microspheres were injected into hindlimb muscles in rats, and these constructs resulted in slow release of VEGF over a period of seven days and evidence of vascular remodeling at time points as long as 70 days after a single injection [ 16]. In another application, VEGF-loaded microspheres were incorporated into alginate hydrogels to generate an injectable, slow-release hybrid delivery system [ 17]. This strategy lead to sustained release of VEGF over 28 days and marked improvement in angiogenesis and limb-sparing in a mouse model of hindlimb ischemia. In a recent report, a degradable VEGF-releasing hydrogel was created by fusing VEGF to the coagulation factor fXIIIa which was then crosslinked into fibrin hydrogels [ 18]. This construct exhibited a controlled degradation and VEGF release over a four week period, and yielded improved angiogenesis, perfusion, and healing in hind limb ischemia and in wound healing models.

In addition to its rapid clearance, recombinant VEGF produced in bacteria or yeast must be purified by a laborintensive chromatographic protocol [ 19, 20]. In a yeast expression system, yields of $40 \mathrm{mg}$ of VEGF 121 per L of culture have been reported using a nickel chromatography purification protocol [ 20]. However, chromatographic purification protocols are challenging to scale up to therapeutic production capacity, and the tooling required to do so contributes to increasing the manufacturing cost of goods (COGs).

Here we have developed a VEGF purification and delivery system ( vEGFPADS) achieved by fusion of VEGF to a thermally responsive biopolymer via a flexible diglycine linker. Elastin-like polypeptide (ELP) is a genetically engineered protein consisting of a five amino acid repeating sequence [21]. This polypeptide has several unique properties that make it useful as a therapeutic delivery platform. First, it is thermally responsive, existing as a soluble protein below a characteristic transition temperature but self-associating into aggregates above that transition temperature [ 22]. This aggregation process is fully reversible. Second, ELPs can be expressed in bacterial recombinant expression systems, and they are easily purified due to their thermally responsive properties [ 23, 24]. After recombinant expression and cellular lysis, ELP can be specifically separated from the soluble bacterial lysate by simply heating the solution or increasing the salt concentration in order to trigger ELP aggregation. Repeated centrifugation steps at temperatures above the ELP transition temperature leads to isolation of very pure preparations of the polypeptide. Third, because they are genetically engineered, the ELP sequence is easily modified to achieve the desired ELP size and transition temperature [22], and therapeutic proteins or peptides and targeting agents are easily fused to the ELP gene to create chimeric therapeutics [ 24-29]. Finally, because of its large size and its biocompatibility, ELP has many properties desired in a drug delivery vector, including a long plasma half-life [ 26 , 30], low immunogenicity [ 31, 32], and biodegradability.

Here we show, using a simple non-chromatographic purification protocol, isolation of ${ }_{\text {VEGF PADS as highly purified }}$ protein in yields up to $90 \mathrm{mg} / \mathrm{L}$ of bacterial culture. The purification requires only a warm water bath and a centrifuge and can be completed in $4-6$ hours. The VEGFPADS retained full VEGF activity as assessed using endothelial cell proliferation, migration, and tube formation assays. Also, VEGFPADS exhibited a slower renal 
clearance and an altered biodistribution relative to unconjugated VEGF. We believe VEGFPAS, or growth factor PADS in general, represent a new, simple way to purify recombinant growth factors. They have the potential, either as stand alone agents or in combination with the novel controlled release methods recently described, to function as stabilized agents for therapeutic angiogenesis.

\section{Methods}

\section{Generation of constructs}

The coding sequence for VEGF 121 was synthesized with codons optimized for expression in E. coli (Life Technologies), and inserted into a plasmid vector between NdeI and BamHI restriction sites, with an SfiI site at the $\mathrm{N}$-terminus of the VEGF ${ }_{121}$ coding sequence. The entire coding sequence was cloned into pET $25 \mathrm{~b}+\mathrm{at}$ the NdeI and BamHI sites, and the ELP coding sequence was excised from pUC19-ELP and cloned into the SfiI site, generating an in-frame fusion of ELP and VEGF 121 . The ELP sequence contained 160 VPGxG repeats in which the $\mathrm{x}$ residue was $\mathrm{V}, \mathrm{G}$, or $\mathrm{A}$ in a 1:7:8 ratio. All constructs were confirmed by DNA sequencing.

\section{Purification of VEGFPADS}

pET25b + vectors containing the VEGFPADS coding sequence were transformed into E. coli BLR(DE3), and $500 \mathrm{~mL}$ cultures were grown for $16-20$ hours in $2 \mathrm{~L}$ flasks. The pET system produces low-level recombinant protein expression even without induction [ 33]. Cells were harvested by centrifugation, lysed by sonication, and nucleic acids were precipitated with polyethyleneimine and removed by centrifugation. $\mathrm{NaCl}$ was added to the soluble lysate to a concentration of $200 \mathrm{mg} / \mathrm{mL}$, and the solution was heated at $42^{\circ} \mathrm{C}$ until the ${ }_{\mathrm{VEGF}} \mathrm{PADS}$ precipitated. The precipitated ${ }_{\text {VEGF }} P A D S$ were collected by centrifugation, re-dissolved in cold PBS, centrifuged at $4^{\circ} \mathrm{C}$ to remove any un-dissolved precipitate, and this heat cycling process was repeated $3-5$ times until purified protein was obtained. Purity was assessed by SDS-PAGE.

\section{Cell culture}

Human umbilical vein endothelial cells (HUVECs) were obtained from ATCC and maintained in M200 medium plus low serum growth supplement (Life Technologies) in a humidified $37^{\circ} \mathrm{C}$ incubator at $5 \% \mathrm{CO}_{2}$. All experiments were performed on cells with $<10$ passages in culture. Cells were removed from flasks by trypsinization and counted using a Scepter® hand held cytometer (Millipore).

\section{HUVEC proliferation assay}

HUVECs were plated in 96 well plates $(10,000$ cells/well). Cells were serum and growth factor starved for $24 \mathrm{~h}$ in M200 medium without supplements then exposed to the indicated concentration of VEGF ${ }_{121}$ (ProSpec) or VEGFPADS for $72 \mathrm{~h}$. Cell number was determined using the MTS aqueous cell proliferation assay (Promega). Experiments were performed in quadruplicate, and the data represent the mean \pm s.e. of 3 independent experiments.

\section{HUVEC tube formation assay}

Sterile, non-tissue culture treated 24 well plates were coated with growth factor reduced Matrigel (BD Biosciences). 50,000 growth factor starved HUVECs were added per well in M200 growth medium $+0.1 \mathrm{mg} / \mathrm{mL}$ heparin without

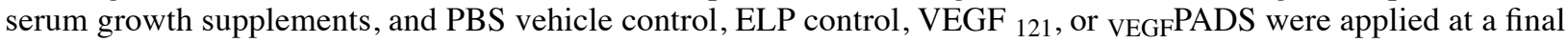
concentration of $20 \mathrm{nM}$. Cells were incubated for $6 \mathrm{~h}$ at $37^{\circ} \mathrm{C}$, then cells were imaged with an inverted brightfield microscope and 10x magnification objective. Five non-overlapping fields were imaged per well, and the number of tubes per field were counted and averaged for each well. Only tubes connecting two cell nodes were counted. Data represent the mean \pm s.e. of three independent experiments.

\section{HUVEC migration assay}

HUVECs $(30,000$ cells/well) were placed in the upper well of Boyden chambers with $8 \mu \mathrm{m}$ membrane pores coated with Matrigel (Corning BioCoat ${ }^{\mathrm{TM}}$ ) in M200 medium $+1 \%$ fetal bovine serum $+0.1 \mathrm{mg} / \mathrm{mL}$ heparin. The lower

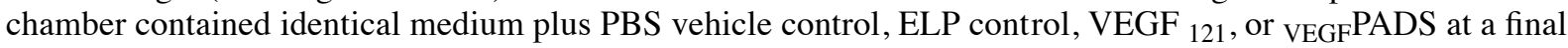
concentration of $10 \mathrm{nM}$ or $50 \mathrm{nM}$. Cells were incubated for $16 \mathrm{~h}$ at $37^{\circ} \mathrm{C}$. The cells on the upper surface of membranes were scratched off using cotton Q-tips. Membranes were removed, stained with $0.1 \%$ crystal violet in $10 \%$ ethanol, and the number of cells on the lower membrane surface were counted in four independent fields per membrane. Experiments were performed in duplicate, and data represent the mean \pm s.e. of three independent experiments.

\section{Polypeptide labeling}


VEGF ${ }_{121}$ (ProSpec) or ${ }_{\text {VEGF }}$ PADS were dissolved at $100 \mu \mathrm{M}$ in $0.1 \mathrm{M} \mathrm{NaHCO}{ }_{3}$ buffer, pH 8.3, and Alexa Fluor $633 \circledR$ succininimidyl ester (Life Technologies) was added to a final concentration of $300 \mu \mathrm{M}$. The reaction was allowed to proceed for $1 \mathrm{~h}$ at room temperature, then unreacted dye was removed by multiple washes with an Amicon 3,000 molecular weight cutoff spin filter (Millipore). Labeling efficiency was determined spectrophotometrically using a method modified from [ 24]. Removal of unreacted label was confirmed by TCA precipitation of the labeled protein and assessing the free fluorophor levels in the supernatant spectrophotometrically.

\section{Pharmacokinetics and biodistribution}

All animal use was approved by the Institutional Animal Care and Use Committee at the University Of Mississippi Medical Center and was carried out in accordance with the National Institutes for Health Guide for the Care and Use of Laboratory Animals. All procedures were carried out under full surgical isoflurane anesthesia. C57Bl/6 mice were catheterized in the femoral artery, and $123 \mathrm{nmol} / \mathrm{kg}$ AlexaFluor 633 - labeled VEGF ${ }_{121}$ or ${ }_{\text {VEGF PADS were injected }}$ in the opposite femoral vein. Blood was sampled intermittently for a period of four hours. Four hours after injection, the animals were euthanized and the tissues removed for ex vivo fluorescence analysis.

Plasma fluorescence was determined by direct measurement of the fluorescence intensity of $2 \mu \mathrm{L}$ plasma samples with $610 \mathrm{~nm}$ excitation and $660 \mathrm{~nm}$ emission using a fluorescence plate reader and a Nanoquant ${ }^{\circledR}$ plate (Tecan). Standard curves of the injected proteins were produced using known quantities of the injectate, and standards were scanned using the same scan settings as were used for plasma samples. Plasma fluorescence intensity was fit to the standard curves to determine the molar plasma concentration at each time point, and data were averaged for all animals ( $n=4$ mice per group) and represented as mean \pm s.d. Averaged plasma clearance data were fit to a two compartment pharmacokinetic model as described previously [ 25].

Whole organ ex vivo fluorescence imaging was performed using an IVIS Spectrum (Caliper Life Sciences, Perkin Elmer) with $605 \mathrm{~nm}$ excitation, $660 \mathrm{~nm}$ emission, and auto exposure. Mean fluorescence radiant efficiency was determined for each organ using Living Image Software (Caliper). $100 \mu \mathrm{L}$ of each protein standard were placed in wells of a black 96 well plate and imaged with the same settings as were used for tissue imaging. Background autofluorescence from tissues of uninjected animals was subtracted from each organ's fluorescence, and mean fluorescence radiant efficiency of all organs were fit to the standard curve values to determine tissue concentrations. Data were averaged for all animals $(n=4$ mice per group) and represented as mean \pm s.e.

\section{Statistical analysis}

Proliferation data were assessed using a two way ANOVA for polypeptide agent and concentration factors, and a Bonferroni multiple comparison was performed. Tube formation and migration data were assessed using a one-way ANOVA with a post hoc Bonferroni multiple comparison to compare treatment groups. Differences in urine levels were compared using a Student's t-test. Organ biodistribution was assessed with a two way ANOVA for factors of polypeptide treatment and organ type, and a Bonferroni multiple comparison was used to assess significant differences. In all analyses, a p value of $<0.05$ was considered statistically significant.

\section{Results and discussion}

\section{Purification and activity of VEGFPADS}

The coding sequence for VEGF 121 was cloned into a pET expression vector in frame with the ELP coding sequence to enable recombinant production. The chimeric ELP-fused VEGF ( vEGFPAD) was purified by taking advantage of the thermally responsive property of the ELP moiety. After bacterial lysis, the ${ }_{\mathrm{VEGF}}$ PADS were separated from other soluble proteins by increasing the salinity of the solution and raising the temperature, which induces a reversible aggregation of the ELP domain. Centrifugation under these conditions selectively precipitated the ${ }_{\text {VEGFPADS, and }}$ they were re-solubilized by mixing in cold phosphate buffered saline. As shown in Figure $1 \mathrm{a}$, three thermal precipitation cycles were sufficient to produce highly purified ${ }_{\mathrm{VEGF}} \mathrm{PADS}$, and they migrated on a polyacrylamide gel at approximately the expected molecular weight. This method routinely yielded at least $90 \mathrm{mg}$ of ${ }_{\text {VEGF PADS per }}$ liter of bacterial culture, and the entire purification protocol from lysis to pure protein could be accomplished in less than one day.

\section{Figure 1}


a
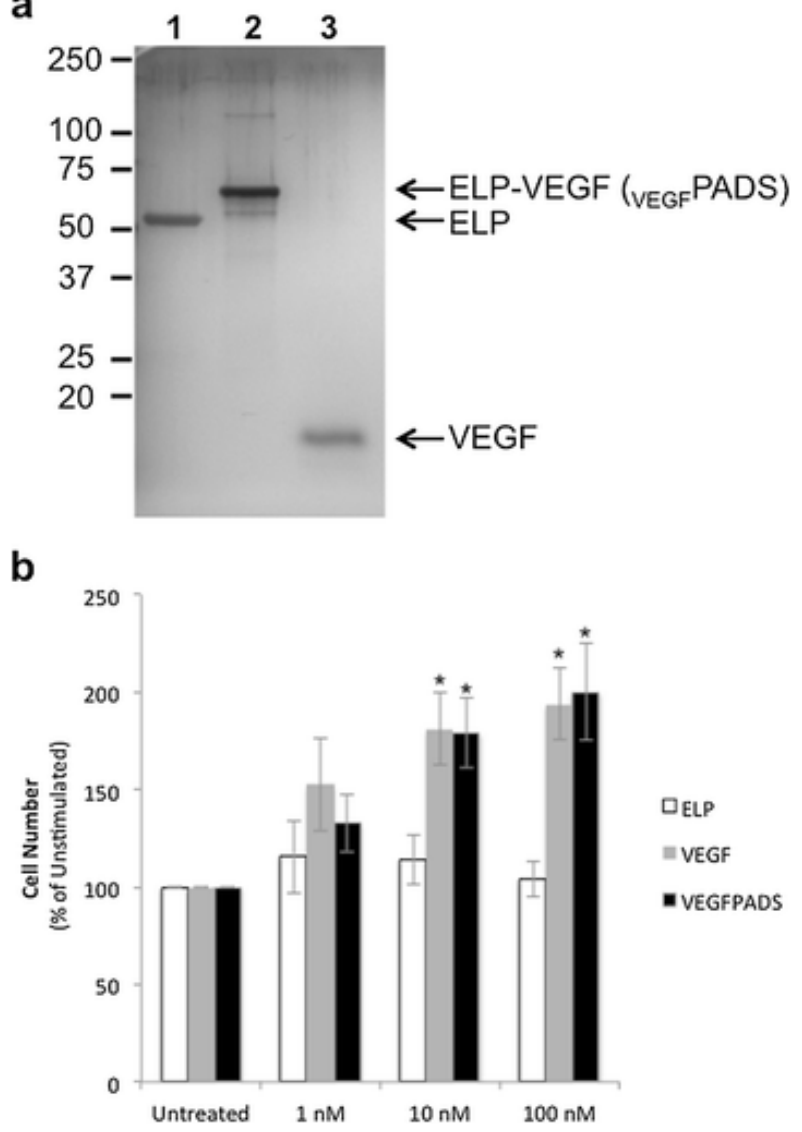

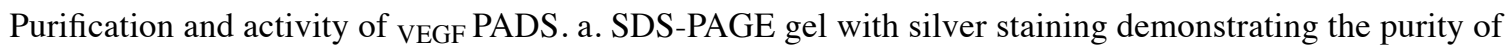
VEGFPADS and ELP control polypeptides. Lane 1, ELP; Lane 2, VEGFPADS; Lane 3, VEGF 121 . b. HUVEC cell proliferation was determined after $72 \mathrm{~h}$ exposure to ELP, VEGF, or ${ }_{\mathrm{VEGF}} \mathrm{PADS}$ at the indicated concentrations using the MTS cell proliferation assay. *Statistically significant increase versus untreated cells $(\mathrm{p}=0.0003$, twoway ANOVA with post-hoc Bonferroni multiple comparison).

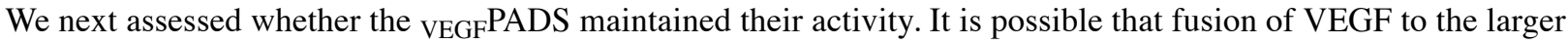
ELP domain could affect its receptor binding and reduce or eliminate its potency. To assess whether VEGFPADS could stimulate proliferation of endothelial cells, HUVECs in culture medium in the absence of growth factors were exposed to a concentration range of either free VEGF or ${ }_{\mathrm{VEGF}} \mathrm{PADS}$. VEGFPADS were very potent stimulators of HUVEC proliferation, achieving significant enhancement of proliferation rate at a concentration of as low as $10 \mathrm{nM}$ (Figure $1 \mathrm{~b}$ ). Importantly, the potency of ${ }_{\mathrm{VEGF}} \mathrm{PADS}$ was equivalent to that of free recombinant VEGF 121 in this proliferation assay.

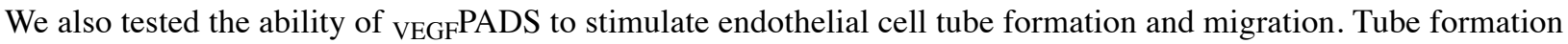
was assessed using a growth factor reduced Matrigel assay. When plated on growth factor reduced Matrigel, HUVECs did not efficiently form tubes (Figure $2 \mathrm{a}$, left panel). However, when the medium was supplemented with

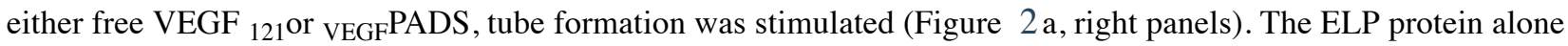
without VEGF fusion had no effect on tube formation. Tubes were counted for each treatment group, and this analysis revealed that ${ }_{\mathrm{VEGF}} \mathrm{PADS}$ were equally as potent as free VEGF ${ }_{121}$ at stimulating HUVEC tube formation (Figure $2 \mathrm{~b}$ ). In addition to tube formation, VEGFPADS also stimulated HUVEC migration. As shown in Figure 3 a,

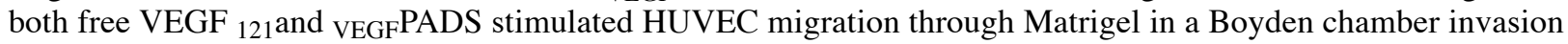
assay. Both proteins stimulated migration at concentrations as low as $10 \mathrm{nM}$ and produced equipotent and statistically significant migration at $100 \mathrm{nM}$ (Figure $3 \mathrm{~b}$ ).

\section{Figure 2}


a

Control

ELP

VEGF

VEGFPADS
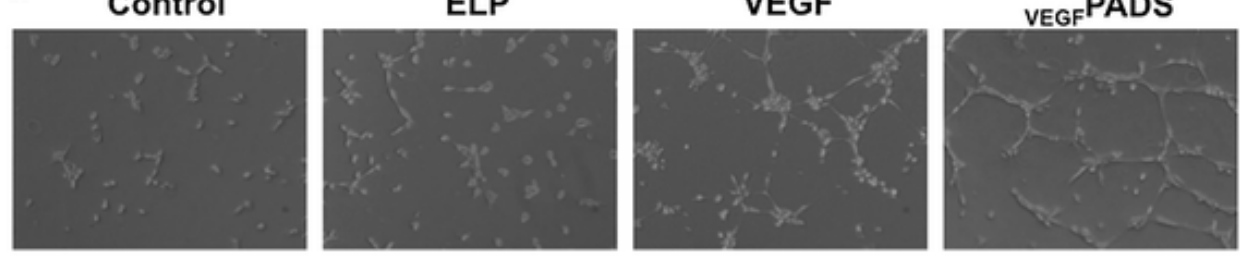

b

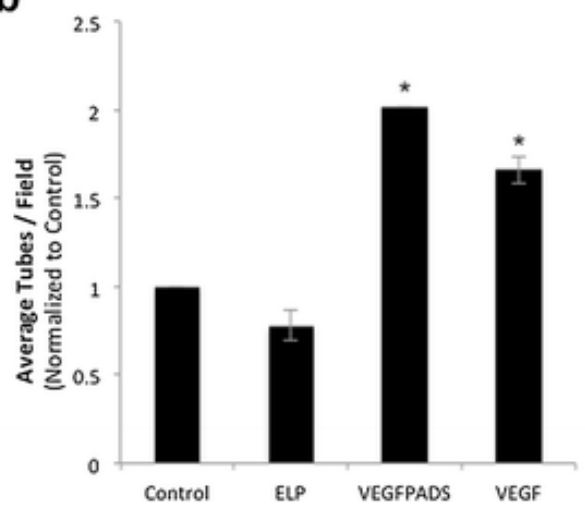

VEGF PADS stimulate tube formation in HUVECs. a. HUVEC tube formation was assessed $6 \mathrm{~h}$ after seeding on growth factor reduced Matrigel and supplementing the media with $20 \mathrm{nM}$ ELP, VEGF, or VEGFPADS. b. Average tubes per field were counted for six fields per sample. Data represent the mean \pm se of four independent experiments. $* \mathrm{p}=0.000003$, one-way ANOVA with post-hoc Bonferroni multiple comparison.

Figure 3 

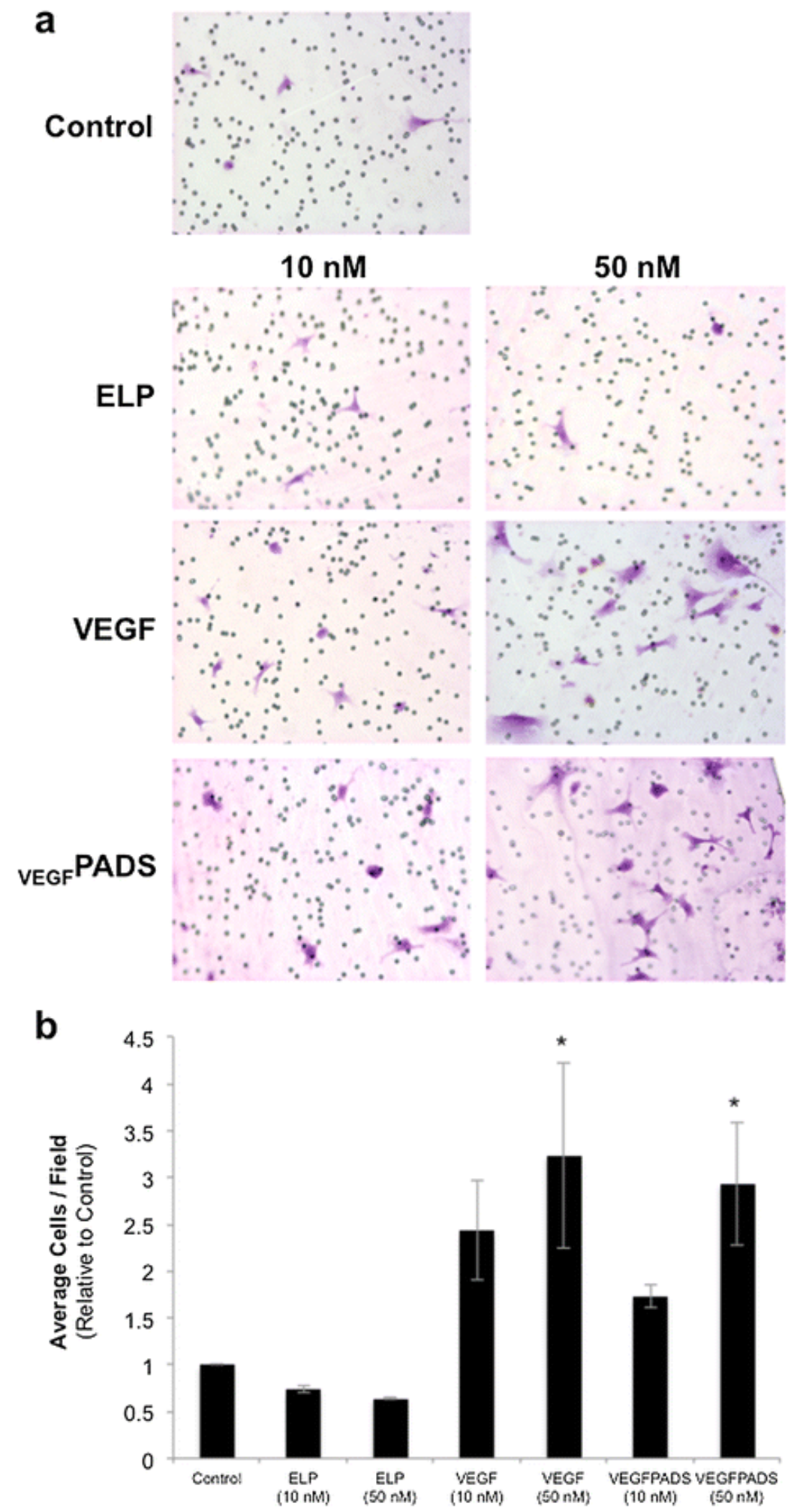

VEGF PADS stimulate HUVEC migration. a. HUVEC migration was assessed $16 \mathrm{~h}$ after seeding in the top chamber of Matrigel-coated Boyden chambers in minimal media and supplementing the bottom chamber minimal media with ELP, VEGF, or VEGFPADS at the indicated concentrations. b. Average cells per field were counted for four to seven fields per sample. Data represent the mean \pm se of three independent experiments. ${ }^{*} \mathrm{p}=$ 0.002 , one-way ANOVA with post-hoc Bonferroni multiple comparison.

\section{Pharmacokinetics and biodistribution of VEGFPADS versus free VEGF}

In addition to examining the ${ }_{\mathrm{VEGF}} \mathrm{PADS}$ activity in vitro, we also determined the pharmacokinetics (PK) and biodistribution of ${ }_{\text {VEGF PADS in comparison to free VEGF }}{ }_{121}$. Both free VEGF 12 and $_{\text {VEGF }}$ PADS were fluorescently labeled, and their PK and biodistribution were determined in mice after bolus intravenous administration. Free VEGF 121 had a very rapid plasma clearance (Figure $4 \mathrm{a}$ ), and fitting to a 2 -compartment PK model revealed a terminal plasma half-life of approximately 30 minutes (Table 1). This is consistent with other reports of approximately a 30 minute half-life for recombinant VEGF in humans [ 15]. VEGFPADS cleared more slowly than free VEGF ${ }_{121}$ (Figure 4 a). Their plasma clearance rate after IV infusion was about half the rate of free 
VEGF $_{121}$ (Figure $4 \mathrm{~b}$ and Table 1), and as a result, there was less fluorescence detectable in the urine at the end of the experiment (Figure $4 \mathrm{c}$ ). Four hours after the infusion, the biodistribution was determined by ex vivo whole organ fluorescence imaging. VEGF ${ }_{12}$ accumulated most highly in the kidneys and the liver and had very low levels in other organs. In contrast, VEGFPADS accumulated more highly in the spleen and liver than did free VEGF 121 , and

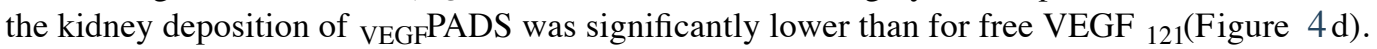

Figure 4
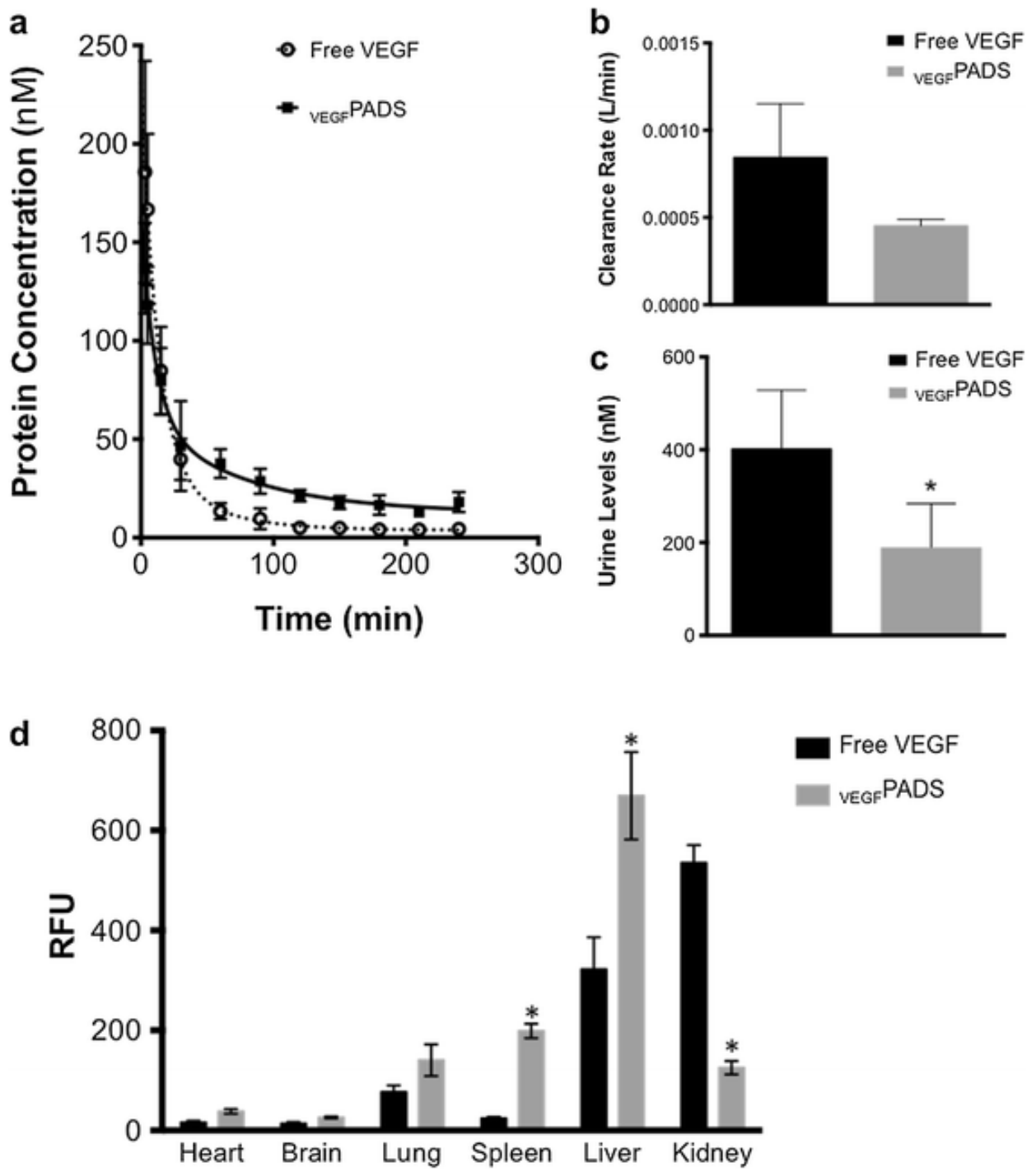

VEGF PADS pharmacokinetics and biodistribution. a. Fluorescently labeled free VEGF or VEGFPADS were administered by IV injection to C57/B16 mice. Plasma levels were determined by direct fluorescence quantitation and fit to a two-compartment pharmacokinetic model. b. VEGFPADS had a slower plasma clearance rate than free VEGF, as was evidenced by lower levels in the urine at the end of the experiment $c$. Data represent the mean $\pm \mathrm{sd}$ of four mice per group. ${ }^{*} \mathrm{p}=0.03$, Student's t-test. $d$. ELP fusion significantly altered the biodistribution of VEGF, increasing its levels in the spleen and liver and reducing its levels in the kidney. * $\mathrm{p}<0.05$, two-way ANOVA with post-hoc Bonferroni multiple comparison.

\section{Table 1}

\begin{tabular}{l|l|l|l|l}
\hline & & & \multicolumn{1}{|c}{ Free VEGF } & \multicolumn{1}{c}{ VEGF PADS } \\
\hline Central compartment volume of distribution & $V_{c}$ & $(\mathrm{~L})$ & $0.013 \pm 0.005$ & $0.013 \pm 0.003$ \\
Plasma clearance & $C l$ & $\left(\mathrm{~L} \mathrm{~min}^{-1}\right)$ & $0.0008 \pm 0.0003$ & $0.0004 \pm 0.0004$ \\
Area under curve & $A U C$ & $\left(\mathrm{nmol} \mathrm{min} \mathrm{L}^{-1}\right)$ & $3,863.8 \pm 1,444.6$ & $5,059.0 \pm 528.5$ \\
Distribution half life & $t_{1 / 2 \text { dist }}$ & $(\mathrm{min})$ & 8.6 & 7.2 \\
Terminal half life & $t_{1 / 2 \text { term }}$ & $(\mathrm{min})$ & 30.2 & 52.4 \\
\hline
\end{tabular}


We also confirmed that the pharmacokinetic and biodistribution results were not influenced by release of the dye

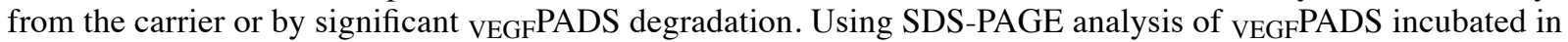
plasma at $37^{\circ} \mathrm{C}$ in vitro for up to $24 \mathrm{~h}$ (Additional file 1: Figure S1a), we determined that the protein undergoes a slow degradation. By measuring the percentage of fluorescence present in bands less than $50 \mathrm{kDa}$, VEGFPADS degraded at a rate of about $10 \%$ per day (Additional file 1: Figure S1b). This value is consi stent with our observations of related ELP-based proteins in a rat model in vivo [ 34] and with the rate observed for the parent ELP carrier in a mouse model using a radiolabeling technique [35]. Also, the rate of degradation is much slower than the plasma clearance rate, indicating that protein degradation is not a major factor on the time scale of the in vivo pharmacokinetic measurements. Protein biodegradation is likely the mechanism by which VEGFPADS are eventually cleared from deposits within tissues, but this process will occur over a matter of days. Finally, by measuring the fluorescence of the protein/plasma mixture before and after TCA precipitation, we observed that less than $2 \%$ of the fluorophor was released from the protein over the course of a $24 \mathrm{~h}$ incubation in plasma (Additional file 1: Figure S1b).

In summary, by fusing VEGF to an engineered polypeptide carrier, we created a chimeric protein that is very easily purified from a recombinant expression system and maintains full VEGF activity as assessed in human endothelial

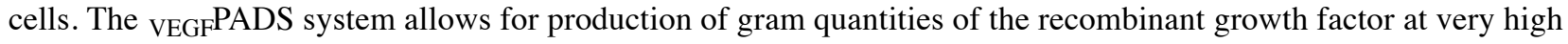
purity with a very simple purification scheme. This could represent a mechanism to facilitate the production of growth factors in a fast and inexpensive manner to make them more accessible for research purposes or to produce them at the scale needed for therapeutics. The system can easily be modified for the production of other growth factors, and we are in the process of generating other VEGF isoforms as ELP fusions as well as other ${ }_{\text {GFPADS using }}$ several growth factors of interest for various diseases. In addition to maintaining their signaling ability, VEGFPADS also showed extended plasma life and altered biodistribution compared to the free growth factor. Given their ease of

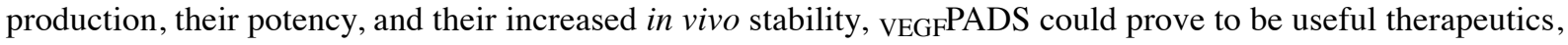
either as standalone agents or in combination with the controlled release strategies described above.

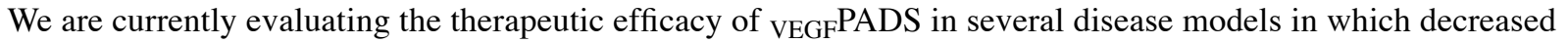
VEGF levels have been implicated. For example, in preeclampsia, a major contributor to the maternal hypertension and other symptoms is the VEGF antagonist sFlt-1 [11]. We have recently described the ability of the ELP carrier to prevent placental transfer and fetal exposure of attached cargo [34], and we are evaluating the ability of VEGFPADS to bind the excess sFlt-1 and restore the available VEGF levels while preventing fetal exposure to VEGF in a rodent preeclampsia model. Also, VEGF has been demonstrated to increase microvascular density and partially restore renal function in a swine model of renovascular hypertension [6]. We are currently evaluating the ability of VEGFPADS to increase the VEGF bioavailability after systemic or direct intrarenal administration and restore or preserve renal function. Finally, VEGF has been shown to be reduced in the Purkinje layer of the cerebellum in the neurodegenerative disease SCA1 [ 4]. We are currently evaluating the brain deposition, clearance kinetics, and

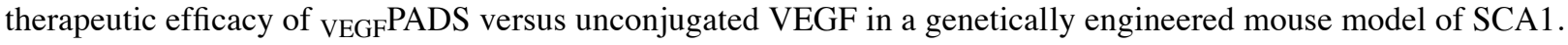

\section{Conclusion}

The work presented here establishes VEGFPADS as easily produced, highly active modifications of recombinant growth factors. The ELP system is easily amenable to modification with any desired proteinacious therapeutic, and

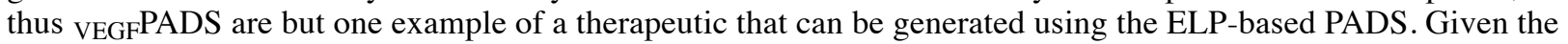
ease of purification and the in vivo stabilization conferred by ELP fusion, we believe VEGFPADS have great potential for therapeutic angiogenesis in a variety of disorders.

\section{Abbreviations}

- ELP: Elastin-like polypeptides

- HUVEC: Human umbilical vein vascular endothelial cells

- PADS: Purification and delivery system

- SCA1: Spinocerebellar ataxia type I

- SDS-PAGE: Sodium dodecyl sulfate polyacrylamide gel electrophoresis

- TCA: Trichloroacetic acid

- VEGF: Vascular endothelial growth factor

- PADS: VEGF Purification and delivery system

\section{Declarations}

\section{Acknowledgements}

Direct funding for this work was provided by National Institutes of Health (NIH) grant R01HL121527 to G.L.B. Partial salary support for E.G. was provided by NIH grant R0OHL116774. Ex vivo specimen imaging 


\section{Additional file}

Additional file 1: Figure S1.

Protein Stability and Dye Release in Plasma. a. The rate of degradation of VEGFPADS was determined after incubation for various times in mouse plasma at $37^{\circ} \mathrm{C}$ by SDS-PAGE analysis. $b$. The percentage of the total band intensity less than $50 \mathrm{kDa}$ was determined for each time point (left axis). Also, dye release was detected by measuring the total plasma fluorescence before and after TCA precipitation of the protein component (right axis).

\section{Competing interests}

The authors have no financial relationship with the organizations that sponsored the research. G.L.B. is owner of Leflore Technologies, $L L C$, a private company working to develop ELP-based therapies for various diseases.

\section{Author's contributions}

EG conceived of the research, designed experiments, and assisted with the writing of the paper. $H L, G R$, and FM performed in vitro experiments. EP assisted with animal experiments. GLB conceived of the research, designed experiments, performed animal studies, analyzed data, and wrote the paper. All authors read and approved the final manuscript.

\section{References}

1. Reuvekamp A, Velsing-Aarts FV, Poulina IE, Capello JJ, Duits AJ. Selective deficit of angiogenic growth factors characterises pregnancies complicated by pre-eclampsia. Br J Obstet Gynaecol. 1999;106:1019-22.

View Article Google Scholar

2. Chade AR, Zhu X, Mushin OP, Napoli C, Lerman A, Lerman LO. Simvastatin promotes angiogenesis and prevents microvascular remodeling in chronic renal ischemia. FASEB J Off Publ Fed Am Soc Exp Biol. 2006;20:1706-8.

View Article Google Scholar

3. Oosthuyse B, Moons L, Storkebaum E, Beck H, Nuyens D, Brusselmans K, et al. Deletion of the hypoxia-response element in the vascular endothelial growth factor promoter causes motor neuron degeneration. Nat Genet. 2001;28:131-8.

View Article Google Scholar

4. Cvetanovic M Patel JM Marti HH Kini AR Opal P Vascular endothelial growth factor ameliorates the ataxic phenotype in a mouse model of spinocerebellar ataxia type 1 Nat Med $20111714457328704010.1038 / \mathrm{nm} .2494$

5. Gilbert JS Verzwyvelt J Colson D Arany M Karumanchi SA Granger JP Recombinant vascular endothelial growth factor 121 infusion lowers blood pressure and improves renal function in rats with placentalischemia-induced hypertension Hypertension 20105538052824248 10.1161/HYPERTENSIONAHA.109.141937

6. Chade AR, Kelsen S. Reversal of renal dysfunction by targeted administration of VEGF into the stenotic kidney: a novel potential therapeutic approach. Am J Physiol Ren Physiol. 2012;302:F1342-50.

View Article Google Scholar

7. Verheyen A, Peeraer E, Lambrechts D, Poesen K, Carmeliet P, Shibuya M, et al. Therapeutic potential of VEGF and VEGF-derived peptide in peripheral neuropathies. Neuroscience. 2013;244:77-89.

View Article Google Scholar

8. Pearlman JD, Hibberd MG, Chuang ML, Harada K, Lopez JJ, Gladstone SR, et al. Magnetic resonance mapping demonstrates benefits of VEGF-induced myocardial angiogenesis. Nat Med. 1995;1:1085-9. 
9. Takeshita S Zheng LP Brogi E Kearney M Pu LQ Bunting S Therapeutic angiogenesis. A single intraarterial bolus of vascular endothelial growth factor augments revascularization in a rabbit ischemic hind limb model J Clin Invest 19949366270293894 10.1172/JCI117018

10. Banai S, Jaklitsch MT, Shou M, Lazarous DF, Scheinowitz M, Biro S, et al. Angiogenic-induced enhancement of collateral blood flow to ischemic myocardium by vascular endothelial growth factor in dogs. Circulation. 1994;89:2183-9.

View Article Google Scholar

11. Maynard SE Min J-Y Merchan J Lim K-H Li J Mondal S Excess placental soluble fms-like tyrosine kinase 1 ( sFlt1) may contribute to endothelial dysfunction, hypertension, and proteinuria in preeclampsia J Clin Invest 200311164958151901 10.1172/JCI17189

12. Zhou Y McMaster M Woo K Janatpour M Perry J Karpanen T Vascular endothelial growth factor ligands and receptors that regulate human cytotrophoblast survival are dysregulated in severe preeclampsia and hemolysis, elevated liver enzymes, and low platelets syndrome Am J Pathol 20021601405233277330 10.1016/S0002-9440(10)62567-9

13. Koga K, Osuga Y, Yoshino O, Hirota Y, Ruimeng X, Hirata T, et al. Elevated serum soluble vascular endothelial growth factor receptor 1 (sVEGFR-1) levels in women with preeclampsia. J Clin Endocrinol Metab. 2003;88:2348-51.

View Article Google Scholar

14. Tsatsaris V, Goffin F, Munaut C, Brichant J-F, Pignon M-R, Noel A, et al. Overexpression of the soluble vascular endothelial growth factor receptor in preeclamptic patients: pathophysiological consequences. J Clin Endocrinol Metab. 2003;88:5555-63. View Article Google Scholar

15. Eppler SM, Combs DL, Henry TD, Lopez JJ, Ellis SG, Yi JH, et al. A target-mediated model to describe the pharmacokinetics and hemodynamic effects of recombinant human vascular endothelial growth factor in humans. Clin Pharmacol Ther. 2002;72:20-32.

View Article Google Scholar

16. Daugherty AL, Rangell LK, Eckert R, Zavala-Solorio J, Peale F, Mrsny RJ. Sustained release formulations of rhVEGF 165 produce a durable response in a murine model of peripheral angiogenesis. Eur J Pharm Biopharm Off J Arbeitsgemeinschaft Für Pharm Verfahrenstechnik EV. 2011;78:289-97. doi:10.1016/j.ejpb.2011.03.011.

17. Shin S-H, Lee J, Lim KS, Rhim T, Lee SK, Kim Y-H, et al. Sequential delivery of TAT-HSP27 and VEGF using microsphere/hydrogel hybrid systems for therapeutic angiogenesis.J Control Release Off J Control Release Soc. 2013;166:38-45.

View Article Google Scholar

18. Sacchi V Mittermayr R Hartinger J Martino MM Lorentz KM Wolbank S Long-lasting fibrin matrices ensure stable and functional angiogenesis by highly tunable, sustained delivery of recombinant VEGF164 Proc Natl Acad Sci U S A 2014111695274024904 10.1073/pnas.1404605111

19. Yang P, Wang K, Shi Z, Dang X, Yu P, Wang C, et al. Prokaryotic expression, purification and activity assay of recombinant vascular endothelial growth factor. Nan Fang Yi Ke Da Xue Xue Bao. 2006;26:1263-8.

View Article Google Scholar

20. Mohanraj D, Olson T, Ramakrishnan S. A novel method to purify recombinant vascular endothelial growth factor (VEGF121) expressed in yeast. Biochem Biophys Res Commun. 1995;215:750-6.

View Article Google Scholar

21. Urry DW, Long MM, Cox BA, Ohnishi T, Mitchell LW, Jacobs M. The synthetic polypentapeptide of elastin coacervates and forms filamentous aggregates. Biochim Biophys Acta. 1974;371:597-602. 
22. Urry DW, Luan C-H, Parker TM, Gowda DC, Prasad KU, Reid MC, et al. Temperature of Polypeptide Inverse Temperature Transition Depends on Mean Residue Hydrophobicity. J Am Chem Soc. 1991;113:4346-8.

View Article Google Scholar

23. Meyer DE, Chilkoti A. Purification of Recombinant Proteins by Fusion with Thermally Responsive Polypeptides. Nat Biotechnol. 1999;17:1112-5.

View Article Google Scholar

24. Bidwell GL, Raucher D. Application of thermally responsive polypeptides directed against c-Myc transcriptional function for cancer therapy. Mol Cancer Ther. 2005;4:1076-85.

View Article Google Scholar

25. Bidwell GL Perkins E Raucher D A thermally targeted c-Myc inhibitory polypeptide inhibits breast tumor growth Cancer Lett 2012319136433536021 10.1016/j.canlet.2011.12.042

26. Bidwell GL Perkins E Hughes J Khan M James JR Raucher D Thermally targeted delivery of a $c$-Myc inhibitory polypeptide inhibits tumor progression and extends survival in a rat glioma model PLoS One 20138 e551043555869 10.1371/journal.pone.0055104

27. Bidwell GL Whittom AA Thomas E Lyons D Hebert MD Raucher D A thermally targeted peptide inhibitor of symmetrical dimethylation inhibits cancer-cell proliferation Peptides 2010 31834412872552 10.1016/j.peptides.2010.02.007

28. Massodi I Moktan S Rawat A Bidwell GL Raucher D Inhibition of ovarian cancer cell proliferation by a cell cycle inhibitory peptide fused to a thermally responsive polypeptide carrier Int J Cancer 2010126533442795124 10.1002/ijc.24725

29. Massodi I, Thomas E, Raucher D. Application of thermally responsive elastin-like polypeptide fused to a lactoferrin-derived peptide for treatment of pancreatic cancer. Molecules. 2009;14:1999-2015.

View Article Google Scholar

30. Liu W, Dreher MR, Furgeson DY, Peixoto KV, Yuan H, Zalutsky MR, et al. Tumor accumulation, degradation and pharmacokinetics of elastin-like polypeptides in nude mice. J Control Release. 2006;116:170-8.

View Article Google Scholar

31. Rincon AC, Molina-Martinez IT, Las HB, Alonso M, Bailez C, Rodriguez-Cabello JC, et al. Biocompatibility of elastin-like polymer poly(VPAVG) microparticles: in vitro and in vivo studies. J Biomed Mater Res A. 2006;78:343-51.

View Article Google Scholar

32. Shamji MF, Betre H, Kraus VB, Chen J, Chilkoti A, Pichika R, et al. Development and characterization of a fusion protein between thermally responsive elastin-like polypeptide and interleukin-1 receptor antagonist: sustained release of a local antiinflammatory therapeutic. Arthritis Rheum. 2007;56:3650-61.

View Article Google Scholar

33. Daniell H, Guda C, McPherson DT, Zhang X, Xu J, Urry DW. Hyperexpression of a synthetic protein-based polymer gene. Methods Mol Biol. 1997;63:359-71.

View Article Google Scholar

34. George EM, Liu H, Robinson GG, Bidwell GL (2014) A polypeptide drug carrier for maternal delivery and prevention of fetal exposure. J Drug Target 1-13. doi:

10.3109/1061186X.2014.950666

35. Liu W, Dreher MR, Chow DC, Zalutsky MR, Chilkoti A. Tracking the in vivo fate of recombinant polypeptides by isotopic labeling. J Control Release. 2006;114:184-92.

View Article Google Scholar 
